\title{
MACUNAÍMA, HORÁCIO E VIRGÍLIO
}

\author{
Maria Augusta Fonseca* \\ "Amigol O campo e o ninho do poeta.. \\ Dews fala, quando a turba cord quleta, \\ As campiras en flor. \\ $[\cdots]^{\prime \prime}$
}

Castro Alves, "Sub tegmine lagi".

"Aperto-lhe a mäo longs, meu amigo, jo que nāo me quer dar o prazer de ve-lo por aqui, a sombra de minhas faias, sub tognine fagi quero dizer, a sombra das minhas mangueiras e de minhas latadas de jasmineiras"

Jose de Alencar, Carta sobre a Confedenaçäo das Tamolos

\section{RESUMO}

Na "Carla pras Icamiabas", capinulo medial de Macunalma o heroj sem nenhum carater de Mdrio de Andrades ampregam-se cectoss das autores latinas Virgtio e Hordcio. Uma discussäo entre tradiçäo e mademidade da tugar a quertöes ligadas a pluralidade de vozes que permeia o discurso desse autor.

Unitermos: discurso mapsodico; wstlo rodio; hibridimo; Hordcio; identidade cultural; modemidade; modemismo; potica da mutilafäo; referencias literdrias, Virglitio.

A rejeiç̧⿸丆口 dos modernistas brasileiros, ora atacando escritores românticos, ora combatendo o estilo bacharelesco de seus antecessores parnasianos, tem o efeito de chocar um gosto estabelecido, desarticular certo pensamento congelado. Apresenta semelhanças com a

* Profa de Literatura Brasileira da UFSC.

Rev. Inst. Est. Bras., SP, 36:67-79, 1994 
"Bofetada no gosto público", manifesto em que o poeta Maiakóvski (1) rechaça Púchkin, Tolstói, Dostoiévski. Arrefecida a bofetada, o que era choque também se transforma em regra. A nova produçăo poética apresenta entăo em sua pluralidade vozes em que o discurso volta a ser desentranhado e retalhado da memória. O movimento de repulsáo e atraçáo do velho, na arte moderna do século XX, seria uma espécie de sucateamento, digamos, do passado no presente. Num jogo complexo de correspondencias, essa inquietaçáo frutificou em Mário de Andrade.

Do ambito datado dos acontecimentos efusivos em torno da Semana de 22 , o artista avança e amadurece o processo do fazer. Sua construçăo narrativa, nos anos que se seguem, diverge da convençăo e mescla relato ficcional e discurso critico. Criar significa desentranhar os proprios monstros, fruto do desvairismo de cada um, e libertar-se dos mítos, da tradiçáo paralisante, num risco de vida e morte. Um exemplo dessa prática é Macunalma o herói sem nenhum carater (2). Dessa obra de Mário de Andrade, particularmente da "Carta pras icamiabas", que constitui seu capitulo IX, e que extraimos algumas citaçós latlnas, seguindo o olhar do artista, para sustentar a reflexáo deste ensaio.

O cruzamento intrincado de farto material, de procedencia variada, faz supor que Mário de Andrade privilegia em Macunalma a construçáo do discurso a partir de uma arqueologia do saber, praticando um exercício de palimpsesto e reconstituindo processos do narrar. Ao articular a magia do novo, arma-se um jogo de forças contrárias, de seduçáo e busca do que foi apagado, rasurado, ao mesmo tempo em que se nega o passado como exigencia do presente. Cruzar esse abismo, e se libertar, e tarefa do sábio. Mas o saber, crivo arbitrário, constitui o pressuposto do julgamento de valor. Mário de Andrade se protege do proprio veneno, aduzindo que e preciso "saber saber". Assim canta no "Lundu do escritor diffcil" (1928): "Todo dificil é fácil//Abasta a gente saber". Esse movimento em muitas direçőes, conhecimento de si e dos outros, comporta novos aprendizados, coser de cantos, trançar de experiencias.

Exemplos dessa postura artística em Mário proliferam na "Carta pras icamiabas". Reconhecida pelo autor como um intermezzo, a Carta é momento único, artificio no fluxo narrativo, aquele em que o narrador-rapsodo enxerta um texto escrito de Macunaíma. Na complexidade da obra a personagem é imitaçáo burlesca de herói, e sua Carta é arremedo (próprio do entremez) de um modo elevado de narrar. Caracte-

1 SCHNAIDERMAN, B. A potica de Malaktrsta. Săo Paulo, Perspectiva, 1971. p.70.

2 LOPEZ, Tele Porto Ancons. org. ANDRADE, Mário de. Macumatmo o henti sem nenhtum cartier. Ediçto critica. UNESCO, 1988. (Col. Archives). 
rizada por um estilo macarrónico, soldam-se no texto do heroi algumas expressoes em latim:

\author{
"capita \\ curriculum vitae \\ urbi et orbe \\ ad hoc \\ horresco referens \\ per amica silentia lunae \\ sub tegmine fagi \\ modus in rebus".
}

Na presente análise distinguem-se as quatro últimas, por serem referências clássicas, fragmentos de dois mestres da tradiçáo latina, os poetas Virgflio (Públio Virgflio ou Vergflio Maro, 70-19 a.C.) e Horácio (Quinto Horácio Flaco, 65-08 a.C.). Indaga-se aqui sobre a adequaçao desses vestígios ao discurso, procurando nos caminhos do fazer princípios e procedimentos que, conscientemente ou náo, orientaram e problematizaram a "filosofia da composiçăo" na poética de Mário de Andrade (3). O travestimento do sério no cómico envolve a Carta de forte marca satírica, de um lado, e distingue em seu conjunto um discurso da diferença.

O fragmento latino horresco referens, que nos remete a Eneida de Virgllio, será utilizado como primeiro exemplo. Localizada a fonte, nos inteiramos de que o missivista Macunaima se apoiou num saber canonizado. A construçăo discursiva que faz pilhando/empilhando outros discursos é técnica conhecida, do longtnquo canto rapsódico ds vanguardas do século $\mathrm{XX}$. Guardadas as profundas diferenças, o próprio poema épico que canta as glorias e desventuras do herói Enéias, as façanhas da guerra e a fuga depois de seu desastre, sustenta-se em matéria alheia. Ja Macunaíma, cauteloso, distingue suas referencias usando aspas. Apesar da fidelidade, suspeita-se que este "heroi de nossa gente" so conheça da obra as passagens mais divulgadas, sem ter procedido à sua leitura. Năo e de estranhar a exibiçăo de conhecimento. Virgflio permaneceu até bem pouco tempo como modelo na tradiçăo literária do Ocidente, comparecendo durante séculos nas antologias escolares. Seu talento criador é celebrado na Divina Comédia, de Dante - e ele o escolhido como guia do Poeta nas regiós infernais - e evocado n'Os Lusiadas, de Camós. Este último destaca uma fração de verso virgiliano, facultando um diálogo com a épica. $O$ episódio usado como paradigma e aquele em que Cassandra, filha de Prlamo e de Hécuba, refugiada no templo de Palas-Minerva, e indignamente ultrajada. Esse verso ecoa em Camōes num episódio igualmente trá-

3 POE, Edgar Allan. The Philosophy of Composition. In: Selected Writings. Londrea, Penguin, 1972 , p. $480-492$ 
gico, em que o tema também é o da súplica a um poder superior. Săo do Livro II da Eneida os seguintes versos:

"Heu nihil invitis fas quemquam fidere divis!

Ecce trahebatur passis Priameia virgo

Crinibus a templo Cassandra adytisque

Minervae,

Ad coelum tendens ardentia lumina frustra;

Lumina, nam teneras arcebant vincula

palmas." (4)

(Ah, quando os deuses sáo contrários, em ninguém é dado o direito de confiar!

Eis que, com os cabelos desfeitos, é arrastada do templo e do santuário de Minerva, Cassandra, a filha de Priamo, debalde seus ardentes olhos aos céus elevado, seus olhos, pois que as măos as cadeias as continham.)

A expressão contida nos dois últimos versos de Virgflio é aproveitada na epopéia camoniana. A remissăo trágica justapóe o modelo para gravar o desespero de Ines de Castro diante de seus algozes. Cumprindo o padrăo clássico, a nova situaçáo de desespero evoca aquele episodio:

Pera o céu cristalino alevantando,

Com lágrimas, os olhos piedosos

(Os olhos, porque as máos lhe estava atando

Um dos duros ministros rigurosos);

Macunaima tambem se apodera de um fragmento de verso da Eneida ao compor sua carta. A fonte inspiradora é, igualmente, o Livro II. O episódio é outro, e a pungência amplificada. Trata-se do fim trágico de Laocoonte e de seus filhos, esmagados por duas serpentes. Eis a passagem de Virgllio:

"Ecce autem gemini a Tenedo tranquilla per alta (Horresco referens) immensis orbibus angues [...]"

(Ora, eis que de Tenedo duas serpentes de imensos aneis pelas águas tranquilas (arrepio-me ao contá-lo) se alongam pelo mar e lado a lado avançam para a praia [...])

4 VIRGILIO. Eneida, w. 402-406. In: Mendes, Odorico. Vigilio Braxileiro. Ediçio bilinglle. Rio de Janeiro/Paris, Gamier, s/d.

5 Todas as traduços do latim contidas neste ensaio săo de autoria do latinista Antonio da Silveira Meindonça.

6 CAMÓES, Luls Vaz de Os Lusfadas Porto, Porto, 1980. p.160.

7 VIRGILIO. Op. cil, v. 203-204. 
Macunaima, eloqüente e sério, grava o parêntese virgiliano em latim. Está ciente da importáncia das citaçōes como persuasăo formal, rótulo de conhecimento, mas nāo atenta para o contexto trágico do verso original. Assim é que faz mençăo às prostitutas da "macota cidade de S. Paulo":

"Tudo isso as donas paulistanas aprenderam com as mestras de França; e mais o polimento das unhas e crescimento delas, bem como aliás "horresco referens", das demais partes corneas dos seus companheiros legais. Deixai passar essa florida ironia." (8)

Na duplicidade de discursos, o sério-cómico tem traços de origem comum com a comédia e a tragedia, ambos cantos em louvor a Baco. De princípios semelhantes, diferiam quanto à imitaçăo. Coadjuvante da primeira, a sátira, diabólica, picante, representava-se nos entreatos (intermezzos) da tragédia, com a funçào de distensionar o espectador. Na construçăo da rapsódia - uma sátira segundo Mário de Andrade -, a comicidade dos casos e a própria linguagem de molde popular, irreverente, descontralda, se articulam à construçăo de uma personagem tragicômica. Envolto por atos e situaçð̋es pandegas, Macunaíma tambem carrega as marcas do padecimento da fome, privações citadinas, mutilado nos mais diversos sentidos, inclusive fisicamente.

No fluxo da Carta, o Livro II da Eneida deixou mais um rastro. Desta vez, numa simples descriçăo do serviço noturno de limpeza da cidade, que segundo Macunaima está a cargo de

"uns antropóides, monstros hipocentáureos azulegos e monótonos, a que congloba o título de Limpeza Pública; que "per amica silentia lunae", quando cessa o movimento e o pó descansa inócuo [...]" (9).

O antídoto contra o mundo dos novos monstros que amedrontam a personagem será lançar máo de um mito congelado, espécie de espantalho. A leitura sugere que Macunafma dá vôos à fantasia e faz da noite o momento do medo, dos ladróes, dos monstros. Mesmo assim, e diffícil conciliar seu discurso com os versos usados para descrever a manobra dos navios gregos, escondidos na calada da noite, esperando o sucesso do cavalo de Epeu na cidadela de Príamo, a trágica hora do ataque, quando sabemos se anuncia o desfecho cruento da guerra:

"Et jam Argiva phalanx instructis navibus ibat

A Tenedo, tacitae per amica silentia Lunae

Littora nota petens; flammas cum regia puppis

Extulerat; [...]" (10).

8 Macunatma o heroi sem nenhum carder. Op. cil p.77.

9 Idem. p. 80.

10 VIRGILIO. Op. cit, v. 254-257. 
( $E$ ja a falange argiva com seus navios alinhados, sob o silencio cúmplice de uma lua calada, partia de Ténedo em direçáo às conhecidas praias, quando da nau capitânea se eleva um facho; $[. .$.$] )$

Articular o discurso com este fragmento, per amica silentia Lunae, implica preparar o espirito do leitor. No entanto, Macunaíma estará ou subvertendo as expectativas, ou confirmando ainda uma vez seu estilo ródio. A segunda hipótese parece mais acertada. Sem ter consciência, esse "filho do medo da noite" (11) é ele próprio o ser dilacerado pela negaçáo que faz de si mesmo. Pois ao reconhecer o outro sobre si próprio, Macunalma assimila o discurso do poder que o domina. Está selada a submissáo, que a Carta documenta, a escravizaçâo por um instrumento do dominador, no caso a palavra escrita.

Ao se entronizar como Imperador (escravizando e escravizado) do Mato Virgem, Macunaima esta se pondo um omamento que the endossa a posiçáo. N5o importa se descontextualizado, o fato é que o discurso se estufa e privilegia uma "aura" vocabular, acentuando o descompasso entre o que diz e como diz. Longino (presumível século I d.C.), adepto do embelezamento das palavras, já via desvantagens no abuso do estilo florido, "poịs empregar em assuntos de pouca monta palavreado grandioso e solene pareceria o mesmo que assentar uma grande máscara trágica numa criancinha" (12).

Multiplicando modos de ver o texto, os fragmentos latinos extrafdos da Carta, do ponto de vista da construçăo rapsódica, estariam acomodando a mescla característica do genero carnavalizado e do discurso dialógico, conforme teoriza o crítico russo Mikhail Bakhtin (13). A leitura dessas citaçoes avança em possibilidades se entendermos, sob essa perspectiva, que a linguagem literária é diálogo de linguagens, um conjunto de muitos hibridos, do qual o autor participa sem linguagem propria. Seus discursos podem aflorar (sem que sejam assumidos pelo narrador) em paródia, sátira, ironia, enfim, como parte desse sistema polifonico. A "visăo por trás" do autor, que nāo fala a linguagem do narrador nem a das personagens, $e$ um fenómeno que Bakhtin identifica nos romances dos tempos modernos.

O Mário de Andrade de 1927 (data em que escreve a rapsódia) usa com maestria essa "visáo por trás", identificada na superposiçáo e justaposiçăo de planos das máscaras e nos desnudamentos, obrigando o leitor ao exerćcio contínuo de "raspar novamente" e de alargar a visăo, para conseguir de ângulos diversos o exame da pluralidade da matéria e construir as muitas historias do texto.

11 Mocunatma o heroi sem nerhum canter. Op. cit ps.

12 LONGINO. Do Sublime In: ARISTÓTEIES, HORÁCIO, LONGINO. A Pactica Classica Slo Paulo, Cultuix, 1988-90. p.99.

13 BAKHTIN, M. Problemas Litodiriosy Enfticos. Havana, Editorial Arte y Literatura, 1986. 
Voltando aquelas fontes que minam seu discurso, é significativo o fato de Macunaíma informar e atestar - "hemos adquirido muitos livros bilingues, chamados 'burros', e o dicionário Pequeno Larousse; e já estamos em condiçăo de citarmos no original latino muitas frases célebres dos filósofos e os testículos da Biblia." Fora as limitaçóes impostas pelo aprendizado recente das linguas da terra ("o portugues escrito e o brasileiro faladon), esse tipo de acesso ao conhecimento, com prática na Carta, reforça que os manuais escolares diluem obras e conceitos, banalizando o aprendizado. E o que se dá com o Macunafma-citadino. Claudica numa comédia de erros, consagra e petrifica a lição de almanaque, como se o apoio nos autores já conferisse credibilidade ao que escreve. No caso da Carta, o Virgflio trágico se esfarela, pulverizando-se em cômico nâo intencional.

Ao inscrever esta Carta pêndega como um estratégico divisor de aguas, Mário de Andrade se vale de um procedimento, de tradiçăo logfnqua: "na 'epopéia medieval' observamos igualmente os intermedios jocosos, o que pode parecer estranho, pois a epopeia medieval adota por modelo formal a Eneida, na qual năo encontramos nada comico." (14) Nota-se que o recurso parece indicar um eco daqueles primeiros entremezes satíricos, representados nos entreatos da tragédia, e que na Idade Média acompanharia a epopéia. Em Macunalma é a composição rapsódica, que por seu caráter irregular, formada de múltiplos de discursos, acomoda aquele procedimento presente na antigũidade e particular do medievo, na utilizaçăo do sério e do cómico.

Mas as outras duas referencias latinas indicam que năo foi so da tradiçāo épica que Macunaíma tirou partido. O Virǵlio poeta dos prazeres da vida campestre, do idflio com a natureza, está nos primeiros parágrafos da Carta, anunciando a tónica do discurso. Assim, ao encerrar uma digressão sobre a língua, Macunafma assevera:

"Mas năo nos sobra já vagar para discretearmos 'sub tegmine fagi', sobre a língua portuguesa, também chamada lusitana. $O$ que nos interessará mais, por sem dávida, [...]".

O empréstimo tanto pode ser das Bucólicas, como das Geórgicas. Sub tegmine fagié o acorde inicial do verso que abre a Écloga I, nas Bucólicas, num diálogo entre Melibeu e Títero:

"Mel. Tityre, tu patulae recubans sub tegmine fagi,

Silvestrem tenui musam meditaris avena: [...]" (15)

(Mel. Tu, Títero, reclinado sob o teto de frondosa faia, entregas-te, com tua leve flauta, à silvestre musa: [...]).

14 CURTIUS, Emst. Liveranara Europtia e Idade Media Latina. Braslia, MECINL, 1979. p.451.

15 VIRGILIO. Bucolicas (ecloga I). In: Op. cil de Odorico Mendes, v.1-2. 
Nas Georgicas, comparece no Livro IV. O fragmento e fecho da

"Illo Virgilium me tempore dulcis alebat

Parthenope, studiis florentem ignobilis oti;

Carmina qui lusi pastorum, audaxque juventa,

Tityre, te patulae cecine sub tegmine fagi." (16)

(Entåo nutria-me a doce Partenope, a mim Virgílio, entregue à paixāo da paz humilde e que, a brincar com versos e pastores, na juventude ousei cantar-te, 6 TYtero, à sombra de frondosa faia.)

Este outro empréstimo de Virgflio está prenhe de subentendidos. Ernst Curtius, sem mencionar autor, obra ou época, menciona os versos de abertura da Écloga I e insiste em que "não é exagerada a afirmaçáo de que falta uma chave da tradiçáo literária da Europa a quem náo saiba de cor essa pequena poesia" (17). Monteiro Lobato, em uma das cartas a Godofredo Rangel, fala de um almoço em S. Paulo em homenagem a Emilio de Menezes, vindo do Rio. Iiustra com uma brincadeira de Juó Bananere (Marcondes Machado), assinalando uma dicçáo de época as avessas, para traduzir a diversăo daquela comilança ao ar livre: sub tegmine as fagi (sic) (18).

Mesmo considerando que a liçăo recitada por Macunaíma procede daqueles resumos antológicos ("os burros"), a alus5̄o permite outros desdobramentos e leva a preocupaçōes mais profundas de Mário de Andrade, um fio condutor da rapsódia, o ócio-preguiça. $O$ rétalho de verso, frase de efeito, é em Virgílio parte de um canto ao exercício da fruiçáo. $O$ diálogo que anteriormente trazia Melibeu aparteando, segue pela voz de TItero:

"Tit. O Meliboee, deus nobis haec otia fecit. Namque erit ille mihi semper deus: illius aram Saepe tener nostris ab ovilibus imbuet agnus. Ille meas errare boves (ut cernis) et ipsum Ludere, quae vellem, calamo permisit agresti."

(Foi um deus, Melibeu, que nos deu esse lazer: pois para mim ele será sempre um deus; amiúde um tenro cordeiro dos nossos apriscos tingira seu altar. Foi ele que, como ves, permitiu que vaguem em liberdade reses e que eu, ao som da flauta agreste, me entregue ao sabor das minhas fantasias.)

16 Idem. Georgicas In: Op. cit, v. 563-566.

17 CURTIUS, Emat Op. cil p.197.

18 LOBATO, Monteiro. Carta a Rangel, de 21-9-1915. In: $A$ barca de Glgre Sáo Paulo, Brasillense, 1959. p.48.

19 VIRGfllo. Bucolicas In: $O p$. citv. 6-10. 
Tudo se move no sentido de um subtexto aflorando na Carta, um jogo entre fruiçăo e inoperancia. Uma passagem de Mário de Andrade, em que reflete sobre a "divina preguiça", endossa a suspeiçăo:

"A preguiça teve sempre, conforme o sentido em que foi tomada, modulaçoes várias. Cada época e cada religiso, aceitando e compreendendo a preguiça segundo o seu modo de ver, decantara-a ou a repulsara. Na Grécia e na Roma de apogeus incontrastáveis, apesar de terem sido estádios de contínua atividade, onde mais se acentuava o prurido dos ideais, as ânsias de perfeiçăo, ela foi apreciada, divinizada quase. [...] A arte nasceu porventura dum bocejo sublime, assim como o sentimento do belo deve ter surgido duma contemplaçăo ociosa da natureza." (20)

Coincidência ou nso, a Écloga I de Virgflio é exatamente a que Mário menciona neste artigo de 1918. Após a passagem em que descreve o ócio-pecado do cristianismo, o autor contra-ataca com o ocio sob o prisma do paganismo:

"O preguiçoso do paganismo é como o Titero de Virgllio que, derreado d sombra das balseiras, (grifo MAF) olhava as suas vacas pascerem longe, tangendo na avena ruda; [...]" (21)

A recuperaçăo do mesmo conceito, atraves de citaçăo de seu próprio repertório, dez anos depois, com o mesmo exemplo, náo pode passar despercebida na leitura de Macunafma.

O olhar se volta ao ócio-preguiça. Oneyda Alvarenga, evocando o "Rito do Irmăo Pequeno" (poema de Mário a Bandeira), faz um corte em seu discurso para sustentar que o "'exerćcio da preguiça' 'entre palavras e deuses', [...] 'exercício da preguiça elevada', parece ter rafzes na formaçáo filosófica de Mário e exige tratamento em profundidade [...]" (22). Na Carta, o fazer está conjugado ao exercício da contemplaçăo. Esse bocejo sublime, que predispóe o poeta a dar vida a arte, referido por Mário de Andrade, também encontra ressonáncia no que Walter Benjamin entende como ócio-preguiça, conjugando-o a predisposiçăo para ouvir e à distensăo que antecede o gerar: "[...] 0 ócio é o grau mais elevado do relaxamento psíquico. $O$ ócio e o pássaro onfrico a chocar o ovo da experiencia. Basta um sussurro na floresta de folhagens para espantá-lo." (23)

20 ANDRADE, Mário de A divina preguiça. In: Bastista, Marta R. et al. I' Tempo Modernista - 1917-1929. Documentaç̧o I.E.B. p. 182.

21 Idem. Op. cit. p.15.

22 ALVARENGA, Oneyda. Mório de Andrade, um pouca. Rto de Janeiro/ Sao Paulo, Jose Olymplo/SCET, 1974. p.105.

23 BENJAMIN, Watter. O narrador. In: Os persadonex SGo Paulo, Abril Cultural, 1975. p. 68. v. XLVIIL. 
O Macunaima urbano, missivista, manifesta-se de modo a ser enquadrado dentro daquela concepção do ócio aplicada ao que Mário designou, no mesmo ensaio, de "far niente burgues e vicioso", preocupado apenas com a conquista fácil (o pedido) do dinheiro para comprar o prazer e se divertir com as prostitutas, nada mais. E o dinheiro se traduz no entender do Macunafma letrado, como sendo "pequeninas e volateis folhas de papel a que o vulgo chamará dinheiro o 'curriculum vitae' da Civilizaçăo, a que hoje fazemos ponto de honra em pertencermos." (24) Torneado à feição rocambolesca, seu texto năo se qualifica como criaçăo artística; ê antes uma compilaçăo inconscientemente distorcida e seguramente pensada para se obter a mercadoria - o cacau das icamiabas.

No quadro das citaçoes latinas resta uma ultima reveladora, fragmento de Horácio, enxertado na Carta - modus in rebus. Na Sátira $I$, de onde provém o exemplo, o tema genérico é a insatisfação permanente entre o que temos e o que queremos. Mecenas é o interlocutor que escuta o poeta:

"Est modus in rebus, sunt certi denique fines, Quos ultra citraque nequit consistere rectum." (25)

(Há uma medida nas coisas, há em suma limites certos · aquém ou além dos quais năo se pode encontrar o bem.)

O tema trabalhado por Horácio gravita em torno do dinheiro, do ouro, da avareza e da cobiça alheia - exatamente do que se ocupa a Carta. Cada um inveja o destino do outro, eis um de seus arcabouços.

Na Carta de Macunafma, modus in rebus (há uma medida nas coisas) vem como reforço aos conselhos que o "heroi de nossa gente"dá às icamiabas. Ou seja, quer sugerir a elas que se apliquem num aprendizado "moderno de mais rendoso gênero de vida", de modo a aumentar os proventos e o tesouro do Imperador, ele proprio, insinuando o interesse de se convidar as "damas" de cá para ensinar as indias nada menos do que o comércio do corpo, razáo pela qual argumenta:

"[...] sempre a existencia de algumas centenas dessas damas entre vơs, muito nos facilitará o "modus in rebus", quando for do nosso retorno ao Império do Mato Virgem [...]" (26)

Macunaíma se apropria aleatoriamente da expressão de Horácio (já de caráter proverbial), expondo a fratura entre a apropriaçăo e o

24 Macunatma o heroi sem nenhum cortiter. p. 74.

25 HORÁCIO. Satira I. In: Le satire di Orazio. Ediçáo billngúue. Itália, Mondadori, 1953. w.106-107.

26 Macumatma o herbi sem nenhum cartice. p. 79. 
modelo original. Uma outra carta de Lobato a Rangel exibe entre graça e ranço erudito o modelo de Horácio: "Fazenda, 23,10,1915 / Rangel: / Est modus in rebus - nem tanto a Candido, nem tanto a Graça. Olhe que se este nos autoriza [...]" (27). Náo obstante as entrelinhas do empréstimo retorcido e tornado comico na Carta, a Sátira I horaciana tem ali outras vozes. Seu contexto sugere um surpreendente paralelismo entre os temas - o dinheiro, avareza e astúcia - e como idéia central da sátỉa a insatisfaçáo irresolvivel, sempre transferida, descontentamento com o que se tem, desejo de ser o outro, de abrir măo de si mesmo para representar o outro, deixando entrever a questăo da identidade. Ainda um ponto sensivel, eco na Carta da mesma Satira I, em que se trata dos propósitos do ataque satírico e de seu alvo.

De um lado volteio de expressăo para tornar opaco o fundamental; de outro, o rumo investigativo se firmando na questăo da identidade e do caráter, na apropriaçăo como um coser de vozes. "O passado é liçăo para se meditar, náo para reproduzir", antecipa Mário de Andrade no Prefácio Interessanttssimo (1921), desacreditando o falso brilho ilustrado. Num artigo datado de 1925, o assunto está em pauta, quando o escritor ensaia interpelar (nđo publica o texto) 0 amigo proximo Oswald de Andrade, sobre "falaçăo" (1924) - um poemasíntese do Manisfesto da Poesia Pau-Brasil - no modo como este altimo ataca a indigência cultural brasileira:

"Toda a história da Penetração e a história comercial da America. Pau-Brasil.

Conta (28) a fatalidade do primeiro branco aportado e dominando diplomaticamente as selvas selvagens. Citando Virgflio para tupiniquins. O bacharel." (29)

Sem deixar de reconhecer a importancia e qualidade artística em Pau-Brasil de Oswald de Andrade, tudo indica, no caso especfifico, que a razáo tende a estar com Mário, quando intercede:

"O. de A. (sic) desbarata com o que cita "Virgilio pros tupiniquins" no mesmo período citando as "selvas selvagens" de Dante pros tupinambás. Questáo de preferência de tribo talvez. Preconceitos pró ou contra erudiçáo năo valem um derréis. O diffcil é saber saber. De resto a Falação exemplifica o que ela táo justamente se revolta contra: é escritura dum naufragado na erudiçáo. Porque essa volta ao material popular, aos erros do povo é desejo de

27 LOBATO, Monteiro. Carta a Rangel, de 23-10-1915. In: Op. cit. p. 54.

28. Na sequéncia, o poema emprega a reiteraçăo da palavra "contra" nos ínicios de algumas estrofes. Isso sugeriria que, talver, tivesse havido equfvoco tipográlico na passagem citada. O contexto, entretanto, parece autorizar a manutençăo de "conta".

29 ANDRADE, Oswald de. Falaçăo. In: Poesia Pau-Brasil S5a Paulo, Globo, 1990. p. 65. 
verdade erudita e das mais. O. de A. sabe delas e num átimo se aternurou sem crítica por tudo o que é do povo, misturando generalizando. E se contradizendo no mesmo escrito que é o unico jeito mesmo de ter contradiçăo." (30)

Mário se refere aos primeiros acordes da Divina Comédia, de Dante Alighieri (Canto I, 2a. estrofe). Eis a fonte da citaçăo manejada por Oswald:

"E quanto, a dir qual era, e cosa dura

Questa selva selvaggia ed aspra e forte

Che nel pensier rinnova la paura!"

A "escritura do naufragado em erudiçăon, em tom paródico e feiçoes avessas, servirá para configurar o pseudo-erudito tapanhumas na carta que escreve as icamiabas, farta de exemplos. Dentro dessa perspectiva, já que o espirito bufáo domina o intermezzo, a critica sobra para todos. E para quem se exclui do ataque, ou mantém um riso distanciado, fica o eco da indagaçáo horaciana safdo da mesma Sátira $I$ "Quid rides? Mutato nomine de te fabula narratur" (32) -, marco na Carta. É atraves dela que Macunafma documenta a ruptura com seus valores culturais e faz profisșáo de fé e conversáo aos valores europeus. Dal o texto travestido, uma espécie (se assim se pode dizer) de hermafroditismo, de que se reveste a propria escritura, sem caráter ela propria, e misto de ópera bufa, mas, além disso, carta de intençóes.

As hipóteses trazidas a análise procuraram refletir sobre a mutilaçăo embrionária na obra. A mutilaçăo, metonimica, é ao mesmo tempo metáfora do discurso e da personagem, expandindo-se para a questáo do caráter, que incide sobre toda esta rapsódia. Ao rejeitar a si mesmo e a seus iguais (o termo icamiabas é "voz espúria" e muiraquită "fere já os ouvidos latinos do vosso Imperador") Macunalma também "fere" o principio de lealdade. Náo reconhecendo mais a voz dos seus, submete-se ao poder alheio. E reconhecimento do outro implicará negaçăo ou mutilaçáo de si mesmo. O deslumbramento de Macunaima deixa aflorar na escrita um vicio do colonizado, em que o "amor bizantino dos livros pareceu, muitas vezes, penhor de sabedoria e de indicio de superioridade mental, assim como o anel de grau ou a carta de bacharel", como se le em Rafzes do Brasil (33).

O diálogo entre textos, como hipótese do trabalho, trouxe a memoria literária usada a partir de duas perspectivas: formula congelada, estropiada ou descontextualizada de um passadismo erudito, de gosto canonizado, e o transporte da memória ao presente, como recor-

30 ANDRADE, Mario de Oswald de Andrade: Pau-Brasil, Sans Parell, Paris, 1925. In:

Bastista, Marta R. et al. Op. cit. p.230. Artigo datado de setembro do meamo ano de 25.

31 ALIGHIERI, Dante Divtna Commedia Milano, Paolo Carrara, 1921. p.19.

32 HORACIO. Op. cit. p.18.

33 HOLANDA, Sergio Buarque Rafzes do Brasil Rio de Janciro, Jost Olympio, 1984. p.122. 
daçăo, estímulo à reflexăo, em que a literatura discute seu fazer. Horácio, na Eplstola aos Pisoes, argumenta que o trabalho do poeta tanto implica o momento da criaçáo como é o resultado de um acúmulo de sua experiencia, exigindo disciplina interior e dominio dos atos criativos. Por isso aconselha: "[...] retenham o poema que năo tenha sido apurado em longos dias por muita rasura, polido dez vezes ate que uma unha aparada năo sinta asperezas." (34) O conselho dá conta de que Horácio, promotor do princípio da mediania - aura mediocritas -, exclui daf os poetas. Estes deveriam ser uma exceçăo. E $\epsilon$ taxativo: "aos poetas, nem os homens, nem os deuses, nem as colunas das livrarias perdoam a mediocridade." (35)

A "poética da mutilaçáo" de Mário acaba por coser muitos cantos e dar forma ao caráter híbrido da formaçáo americana. Seu diagnóstico de Macunafma, em contrapartida, 6 que a ausencia de caráter do "herói de nossa gente" representa uma espécie de ferida aberta no corpo mutilado. Mário de Andrade é cético quanto à cicatrizaçáo dessa fenda, que afinal possibilitaria o reconhecimento de uma identidade, por conseguinte, de um caráter. Mas isso implica a aceitaçáo da diferença, entenda-se, de uma cultura e de uma língua de formaçăo híbrida, mestiçada. $O$ desolamento a esse respeito está num desabafo ao crítico Augusto Meyer (carta de 16-VII-28) sobre Macunalma:

"[...] Se foi escrito brincando, ou melhor, divertidamente, por causa da graça que eu achara no momento entre a coincidencia dum herói ameríndio táo sem caráter e a convicçăo a que eu chegara de que o brasileiro năo tinha caráter moral, além do incaracterístico físico duma raça em formaçăo, se foi escrito divertidamente, a releitura do livro me principiou doendo fundo em seguida. Hoje ele me parece uma sátira perversa. Tanto mais perversa que eu năo acredito que se corrija os costumes por meio da sátira." (36)

\section{ABSTRACT MACUNAIMA, HORACE AND VIRGL}

"Carta pras Icamiabas", medial chapter in Morio de Andrade's Macunatma o heroi sem nenhum caráter, nefers to Latin exeeps from authoss Vigul and Horace $A$ discussion abour the relationship benween tradition and modemily brings forth questions conceming the phurality of voles which pervades the discourse of this Braxilian author.

Keywords: cullural identib; Horaces bybridism; literay references, modemism; poetic of mutilation; thapsodic discouss thodion style; Vigil

34 HORACIO. Ante Pottica. In: ARISTÓTELES, hORÁCIO, LONGINo. A Politea Clásica. Sáo Paulo, Cultrix, 1988-90. p.63.

35 Idem. Op. cit. p.66.

36 Mario de Andrade cecreve cartas a Alceh, Mgyer e Outras Rio de Janeiro, Ed, do Autor, 1968. p.58. 


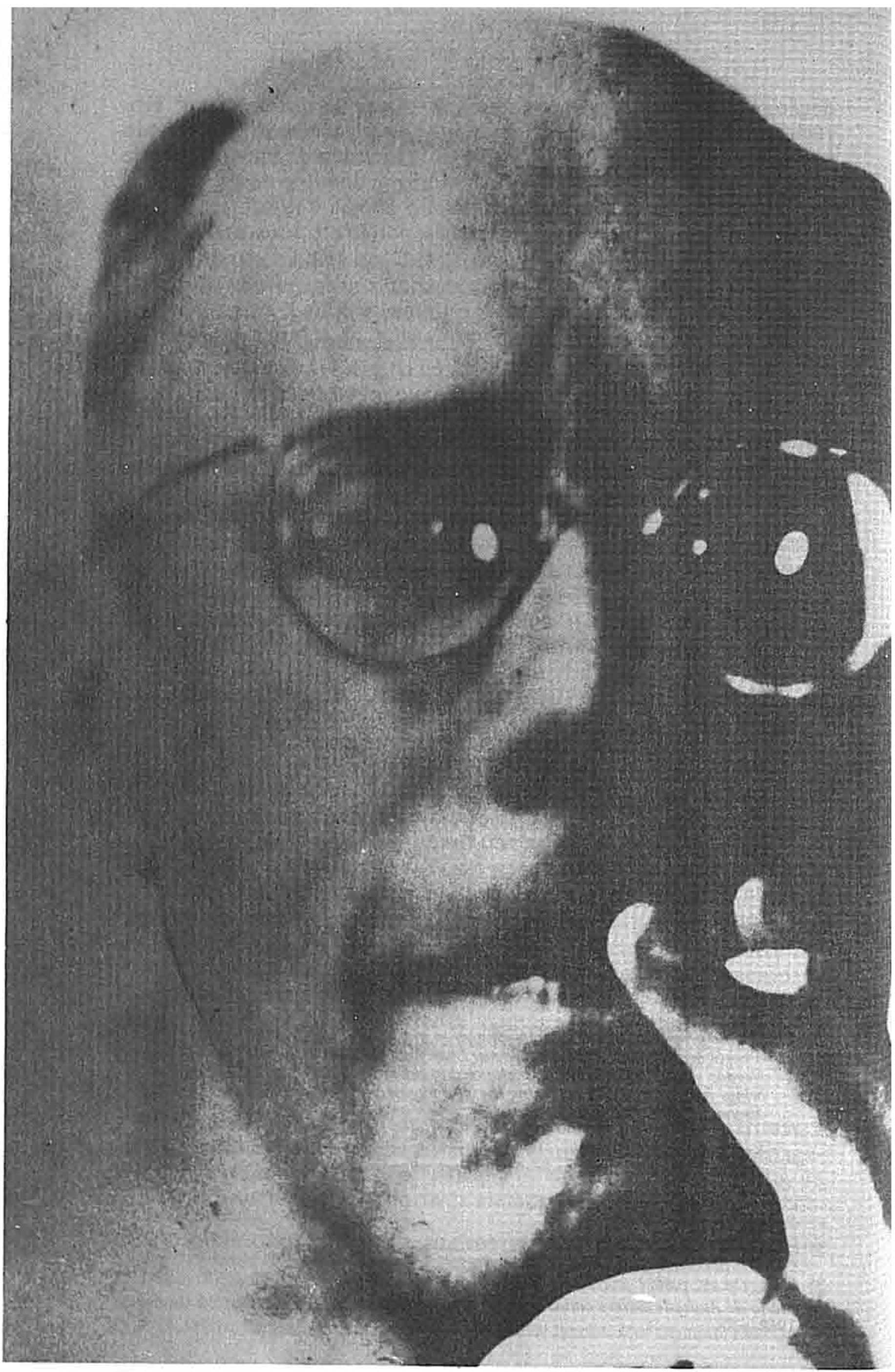

Fev./1945. Foto Gregori Warchavchik. 